Article

\title{
Bimodular Antiparallel G-Quadruplex Nanoconstruct with Antiproliferative Activity
}

\author{
Olga Antipova ${ }^{1, *}$, Nadezhda Samoylenkova ${ }^{2}$, Ekaterina Savchenko ${ }^{2}$, Elena Zavyalova ${ }^{1}{ }^{(}$, \\ Alexander Revishchin ${ }^{2}$, Galina Pavlova ${ }^{2,3,4}$ and Alexey Kopylov ${ }^{1}$ (D) \\ 1 Chemistry Department, Lomonosov Moscow State University, Leninskiye Gory 1-40, 119991 Moscow, \\ Russia; zlenka2006@gmail.com (E.Z.); kopylov.alex@gmail.com (A.K.) \\ 2 Institute of Gene Biology, Russian Academy of Sciences, Vavilova 34/5, 119334 Moscow, Russia; \\ samoylenkova.n@gmail.com (N.S.); savhenko61@mail.ru (E.S.); revishchin@mail.ru (A.R.); \\ lkorochkin@mail.ru (G.P.) \\ 3 Federal State Autonomous Institution (N.N. Burdenko National Scientific and Practical Center for \\ Neurosurgery) of the Ministry of Health of the Russian Federation, 1st Tverskaya-Yamskaya 13/5, \\ 125047 Moscow, Russia; \\ 4 Sechenov First Moscow State Medical University, Institute of Molecular Medicine, B. Pyrogovskaya 2/6, \\ Moscow 119992, Russia \\ * Correspondence: antipovachem@gmail.com; Tel.: 8-(495)-939-3149
}

Received: 29 July 2019; Accepted: 28 September 2019; Published: 8 October 2019

\begin{abstract}
Oligonucleotides with an antiproliferative activity for human cancer cells have attracted attention over the past decades; many of them have a G-quadruplex structure (GQ), and a cryptic target. In particular, DNA oligonucleotide HD1, a minimal GQ, could inhibit proliferation of some cancer cell lines. The HD1 is a 15-nucleotide DNA oligonucleotide that folds into a minimal chair-like monomolecular antiparallel GQ structure. In this study, for eight human cancer cell lines, we have analyzed the antiproliferative activities of minimal bimodular DNA oligonucleotide, biHD1, which has two HD1 modules covalently linked via single T-nucleotide residue. Oligonucleotide biHD1 exhibits a dose-dependent antiproliferative activity for lung cancer cell line RL-67 and cell line of central nervous system cancer U87 by MTT-test and Ki-67 immunoassay. The study of derivatives of biHD1 for the RL-67 and U87 cell lines revealed a structure-activity correlation of GQ folding and antiproliferative activity. Therefore, a covalent joining of two putative GQ modules within biHD1 molecule provides the antiproliferative activity of initial HD1, opening a possibility to design further GQ multimodular nanoconstructs with antiproliferative activity-either as themselves or as carriers.
\end{abstract}

Keywords: DNA G-quadruplex oligonucleotide; nanoconstruct; antiproliferative activity; human cancer cell lines

\section{Introduction}

G-quadruplex (GQ) folded oligonucleotides are capable of inhibiting proliferation of cancer cells, both as themselves and as carriers (see reviews [1-3]). Despite knowing these effects for more than a decade, a tentative molecular mechanism is not known yet—even for the most studied case, DNA GQ AS1411 [1,4,5] - most likely because of a cryptic target. The functional effect of oligonucleotide could be a result of many different events: Binding and modulating cell membrane functioning, penetrating a cell, or specific binding and blocking of functionally important GQ-binding proteins inside a cell, thereby yielding a pleiotropic effect. Some events had been experimentally described, such as blocking the signal transduction, for example [6-10].

15-nucleotide DNA aptamer HD1 was originally selected as thrombin binding aptamer [11], and in the current literature it is normally abbreviated as TBA, despite its original name being HD1. Later, 
an antiproliferative activity of this 15-meric DNA had been discovered [12]. In this publication we will be using the original name HD1, because only antiproliferative properties of this GQ are under study - keeping aside its ability to bind thrombin. The HD1 folds into a minimal chair-like monomolecular antiparallel GQ structure. The HD1 structure is two stacked G-quartets with a potassium cation coordinated in the central cavity $[13,14]$. Coming back to the thrombin story, both destabilization and excessive stabilization of GQ framework significantly reduces the inhibitory activity of the aptamer, most likely via conformational changes in the two TT-loops that interact with thrombin [14].

In the study of Bates, antiproliferative activity of HD1 was discovered [12]. This activity is compared, for example, with one of the AS1411, which is the current leader of antiproliferative GQs [1,5]. Since then, some occasional conditions and a limited number of cell lines were tested. However, no standard conditions have been established yet, therefore not allowing for any uniform results nor any comparative studies to be made.

Treatment of HeLa cells with $10 \mu \mathrm{M}$ HD1 for seven days has decreased the cell viability to $35 \%$ to $60 \%[15,16]$. Antiproliferative activity of $10 \mu \mathrm{M}$ HD1 has been shown for Calu- 6 lung cancer cells: Treatment for one day does not decrease the cell viability; for two days, the cell viability decreases to $60 \%$; and for three days, it decreases down to $30 \%$ [17]. For colon cancer cells HCT116 $6^{-/ \text {p5 }}$ harboring a mutation of the p53 gene, treatment with 10 and $50 \mu \mathrm{M}$ HD1—even for one day—has a notable effect, as the cell viability decreases to $80 \%$ and $25 \%$, respectively [18]. For the majority of studies on the antiproliferative effect of HD1, a $10 \mu \mathrm{M}$ concentration was used. We therefore used this concentration as the 'standard'.

There are a few examples when molecular constructs assembled from separate functional modules retain activity corresponding to the original modules $[19,20]$. The strategy of assembling multimodular constructs by covalent binding of separate functional modules is used, for example, to create conjugates of aptamers with miRNA that have approached a stage of clinical trials [21,22].

Therefore, because HD1 has definite antiproliferative activity, then it is of value to use this GQ module to build bimodular constructs. A minimal version of this construct is a 'tween', made by covalently linking two GQs via a single thymidine residue, producing 31-mer biHD1. Coming back to the story with thrombin, this 'tween' molecule had been thoroughly tested for anti-thrombin functioning under the name RA-36 [23], which has high enough functional activity [24]. A tentative structure of RA-36 has two asymmetrical GQs, where the second module is not an ideal GQ [25,26]. Recently, we learned that the bimodular construct could be made by joining HD1 modules with artificial non-nucleotide linker [27]. Assuming that different parts (pharmacophores) of the same GQ framework of HD1 perform two activities-anti-thrombin and antiproliferative ones-it is impossible to predict the antiproliferative activity of biHD1 in advance.

In addition to biHD1 alone, a series of biHD1 derivatives were tested to find a structure-activity relationship: Whether any GQ alterations would affect antiproliferative activity.

For studies regarding antiproliferative activity of some GQs and HD1, only a few cell lines were applied. Generally, an antiproliferative effect depends on both GQ structure and cell line. Therefore, for the particular study of biHD1, a selection of the proper cell line is required. In addition, a lack of standard conditions for testing has hindered the comparison on published data. Therefore, this study is dedicated to the screening of antiproliferative activity of the bimodular DNA oligonucleotide, biHD1 and derivatives for eight human cancer cell lines_including non-malignant human embryonic fibroblasts as a control—to establish an appropriate model for further studies.

\section{Results}

\subsection{Oligonucleotide Design in Brief}

The nucleotide sequences of HD1, biHD1 and its derivatives are shown in Table 1. A more detailed description of the design of biHD1 and derivatives will be provided in the 'Discussion' section. 
Table 1. Sequences of DNA oligonucleotide biHD1 and its derivatives. The changes are shown in bold; pr-1,3-propanediol residue.

\begin{tabular}{ccc}
\hline Number & Name & ODN Nucleotide Sequence \\
\hline 1 & HD1 & GGTTGGTGTGGTTGG \\
\hline 2 & biHD1 & GGTTGGTGTGGTTGGTGGTTGGTGTGGTTGG \\
\hline 3 & biHD1-C3 & GGTTGGTGTGGTTGGprGGTTGGTGTGGTTGG \\
\hline 4 & biHD1-T4A,T20A & GGTAGGTGTGGTTGGTGGTAGGTGTGGTTGG \\
\hline 5 & biHD1-5'- $\Delta 2 \mathrm{G}$ & TTGGTGTGGTTGGTGGTTGGTGTGGTTGG \\
\hline 6 & biHD1+Ba & GGTTGGTGTGGTTGGTGGTTGGTGTGGTTGG \\
\hline
\end{tabular}

The oligonucleotide biHD1 is a 31-mer, and it was designed by covalently joining two 15-meric HD1s via single thymidine residue. biHD1 was originally proposed as an anti-thrombin aptamer under the name RA-36 [23]. To study antiproliferative activity, in particular, we have focused on the correlation of conformation of the GQ and activity, seeing as anti-thrombin activity and antiproliferative activity are supported by different parts and/or pharmacophores of the HD1 molecule [16-18]. The following series of derivatives were designed; firstly, biHD1-C3 possibly has a reduced reciprocal influence of two GQs; secondly, biHD1-T4A,T20A possibly has less compact GQ structures; thirdly, biHD1-5'- $\Delta 2 \mathrm{G}$ possibly does not have the $5^{\prime}$-terminal GQ; and fourthly, biHD1+Ba possibly has an unusual conformation of GQs [25].

\subsection{Monitoring of biHD1 and Derivatives Conformations}

Interactions of two GQs with each other within biHD1 molecule has been indirectly demonstrated previously [28].

Circular dichroism spectroscopy is a straightforward conventional approach to monitor both GQ folding and its orientations because of highly characteristic spectra of GQ. The CD spectra of biHD1 and its derivatives have shown a topology of antiparallel GQ similar to single-modular HD1-except for biHD1+Ba (Figure 1). The data have supported the possibility of covalently joining two GQs with a single T-nucleotide. Conformation of the initial GQ-modules is not essentially distorted.

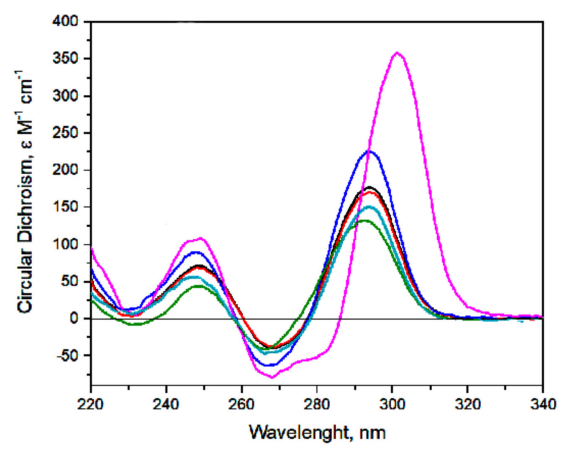

Figure 1. CD spectra of $2.5 \mu \mathrm{M}$ biHD1 and ODNs under the study in $10 \mathrm{mM} \mathrm{NaH} \mathrm{PO}_{4} / \mathrm{Na}_{2} \mathrm{HPO}_{4}, 10 \mathrm{mM}$ $\mathrm{KCl}, 140 \mathrm{mM} \mathrm{NaCl}$, pH 7.5 at $20^{\circ} \mathrm{C}$; biHD1—blue line, biHD1-C3—black line, biHD1-T4A,T20A—red line, biHD1-5'- $\triangle 2 \mathrm{G}$ - green line, biHD1+Ba—purple line, HD1—light blue line.

The molar circular dichroism for biHD1 with $\mathrm{K}^{+}$cation is 1.5 times more than that for HD1, and it has proved the existence of two unequal GQs $[25,26]$.

Replacement of T-nucleotide as a linker with more flexible three-methylene bridge led to a 1.3-time decrease of maximum $294 \mathrm{~nm}$, showing some deviations from the initial conformation of HD1. A decrease of the maximum for two other derivatives correlates with expected distortions of the GQs of biHD1. A decrease of 1.3 times or slightly more of the maximum happened when two base-paired 
thymines of lateral TT-loops had been replaced with two more bulky adenines in biHD1-T4A,T20A. Several other structural distortions were observed for biHD1-5' $-\Delta 2 \mathrm{G}$ with a 1.7 times decrease of the maximum when the first GQ had been destroyed.

biHD1+Ba shows both an increased maximum of the molar circular dichroism and bathochromic shift; its spectrum correlates well with spectra of single-modular HD1 with $\mathrm{Ba}^{2+}$ [25]. The molar circular dichroism for biHD1 is two times more than that for HD1, and it has proved the existence of two GQs that are more proper than in case of $\mathrm{K}^{+}$cation. An increase in the amplitude of the maximum of the CD spectrum and better proportion could be a result of conformational freezing of GQs due to stronger chelation of the guanine bases with barium cations then that with potassium one [29].

\subsection{Antiproliferative Activity}

\subsubsection{Antiproliferative Activity of biHD1}

To reveal the dose-dependent cellular response, three concentrations of biHD1 were tested: 0.1 , 1.0 and $10 \mu \mathrm{M}$. Unsurprisingly, the responses for different cell lines turned out to be different, which suggests that the mechanisms of biHD1 action are not uniform but depend on the cell line nature (Table 2, Figure 2A-C, Figure S2).
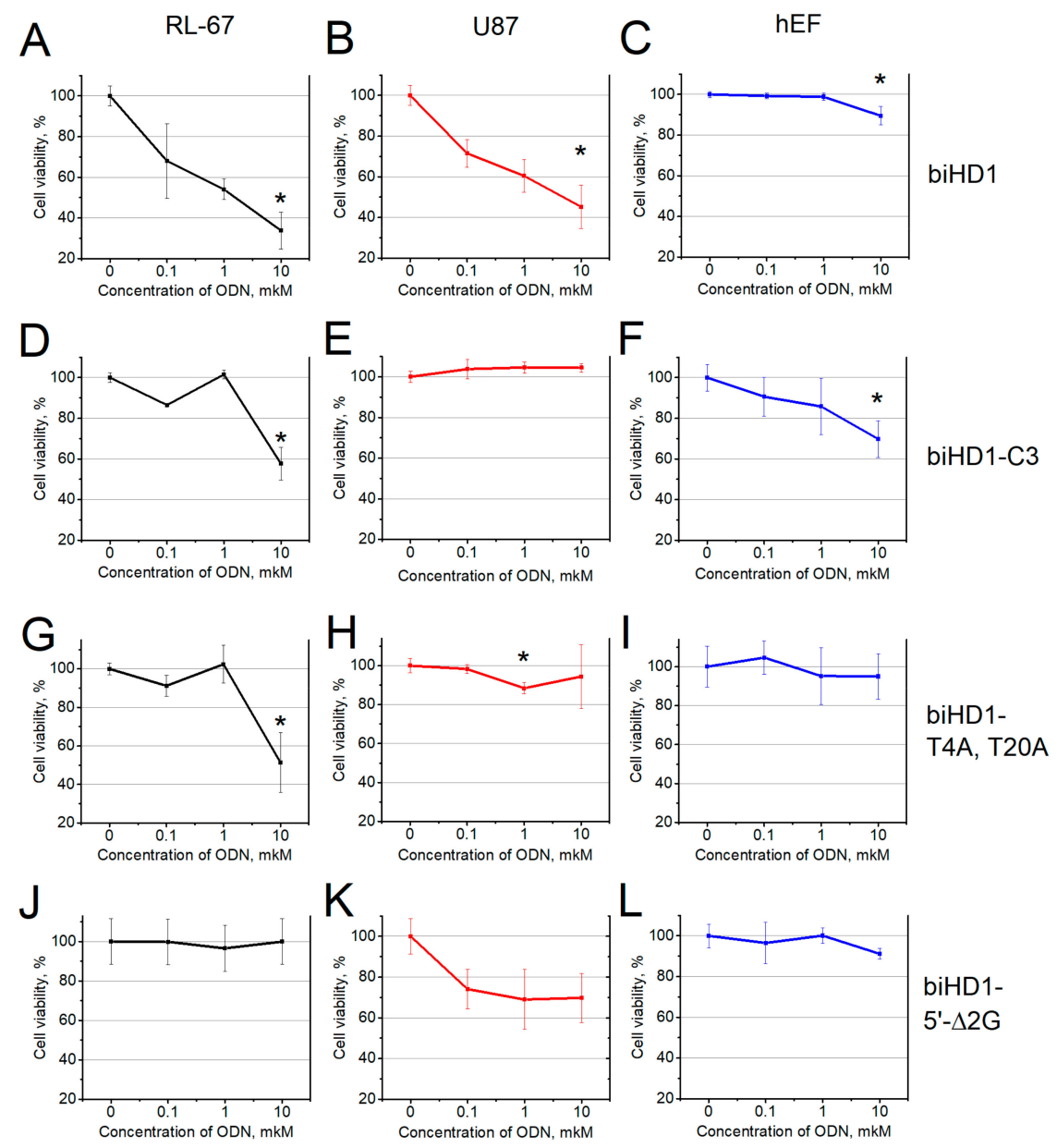

Figure 2. Cell viability according MTT test for oligonucleotides: (A-C)—biHD1; (D-F)—biHD1-C3; (G-I)—biHD1-T4A,T20A; (J-L)—biHD1-5'- 2 2G; results are presented for human cancer cell lines RL-67 (A,D,G,J), U87 (B,E,H,K), and embryonic fibroblasts $(\mathbf{C}, \mathbf{F}, \mathbf{I}, \mathbf{L})$ after $72 \mathrm{~h}$ incubation with different concentrations of oligonucleotides: Control experiment without oligonucleotides, $0.10,1.0$, and $10 \mu \mathrm{M}$. Data are presented as mean \pm S.D. ${ }^{*}$ marks $p<0.05$ compared with control (w/o oligo). 
Table 2. Cell viability after treatment of human cancer cell lines and control cell line with 'standard' concentration of oligonucleotides, $10 \mu \mathrm{M}$. The cell line is listed according to the cell viability after biHD1 treatment. The viability values with less than $70 \%$ are in bold. All data could be found in the Supplement Figures S2-S8. In the biHD1-C3 column, * marks the data for the single-modular HD1.

\begin{tabular}{cccccc}
\hline \multirow{2}{*}{ Cell Line } & \multicolumn{5}{c}{ Cell Viability, $\%$} \\
\cline { 2 - 6 } & biHD1 & biHD1-C3 & biHD1-T4A, T20 & biHD1-5'- $\mathbf{2 G}$ & biHD1+Ba \\
\hline RL-67 & $\mathbf{3 4}$ & $\mathbf{5 8}$ & $\mathbf{5 1}$ & 100 & 103 \\
\hline U87 & $\mathbf{4 5}$ & $104 / 103^{*}$ & 94 & $\mathbf{6 6}$ & 96 \\
\hline HeLa & $\mathbf{5 7}$ & $\mathbf{7 0}$ & 91 & 74 & 86 \\
\hline HCT116 & $\mathbf{5 8}$ & 96 & 105 & 74 & 100 \\
\hline MCF7 & $\mathbf{6 4}$ & 90 & 102 & 85 & 97 \\
\hline mS & 77 & 96 & 93 & 93 & 76 \\
\hline PC3 & 78 & 131 & 91 & 85 & 101 \\
\hline hEF & 90 & $70 / 87^{*}$ & 95 & 91 & 98 \\
\hline
\end{tabular}

The most pronounced effect of the bimodular biHD1 on the cell viability was for lung cancer cells RL-67 (Figure 2A). The effect was dose-dependent; the treatment with $0.1 \mu \mathrm{M}$ biHD1 decreased the cell viability to $70 \%$, while the treatment with $10 \mu \mathrm{M}$ biHD1 decreased it further from $30 \%$ to $40 \%$.

The U87 cell line showed approximately the same dose-dependent response when treated with biHD1 (Figure 2B). All other cell lines were much less sensitive to a low concentration of biHD1, showing measurable effects only when the oligonucleotide was at the 'standard' of $10 \mu \mathrm{M}$ concentration (Figure S2, Table 2). Finally, the non-malignant cell line of human embryonic fibroblasts is weakly sensitive to treatment with biHD1, and a decrease in the cell viability was about $10 \%$ with $10 \mu \mathrm{M}$ biHD1 (Figure 2C).

The antiproliferative activity of biHD1 was independently tested by assessing the change in the number of proliferating cells for U87 in particular, and MCF7 as a control, treated with solutions of oligonucleotide biHD1 of $0.1,1$ and $10 \mu \mathrm{M}$ for $72 \mathrm{~h}$. Figure 3 shows that after incubation of U87 with $10 \mu \mathrm{M}$ biHD1 for $72 \mathrm{~h}$, there is a decrease in a number of Ki-67 positive cells (green versus blue, Figure 3, four upper fields), and there are only a minor changes for the MCF7 line (green versus blue, Figure 3, four bottom fields).
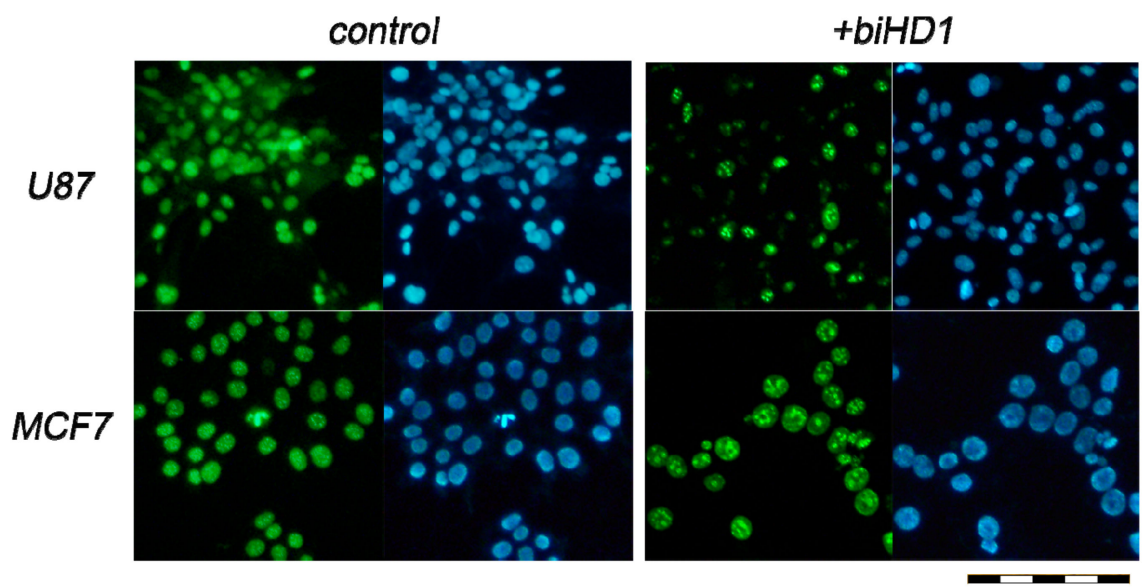

Figure 3. Fluorescence images of U87 cells (up) and MCF7 cells (bottom) incubated with $10 \mu \mathrm{M}$ biHD1 (right panel), and with no oligonucleotide added (control left panel) for $72 \mathrm{~h}$. Proliferating cells were stained with fluorescent Ki-67-antibody, green images; all cells were stained with bisbenzimide nuclear fluorescent dye, blue images. Scale bar for all images $=100 \mu \mathrm{m}$. 


\subsubsection{Antiproliferative Activity of biHD1 Derivatives}

To test the hypothesis that GQ structure is responsible for the antiproliferative activity, a series of biHD1 derivatives were created (Table 2). In Section 2.1., "Oligonucleotide Design in Brief", we introduced a rationale for modulation a structure of GQs of biHD1 to different extents. The three-methylene bridge within biHD1-C3 makes two GQ of initial biHD1 more independent, possibly reducing reciprocal effects. It decreased the antiproliferative effect of biHD1-C3 (Figure 2D-F and Figure S3). For the sensitive cell line, RL-67, the effect of biHD1-C3 is smaller than for the original biHD1: $60 \%$ versus $40 \%$ of cell viability, respectively; and the effect could be seen only at high concentrations of biHD1-C3-10 $\mu \mathrm{M}$. For several cell lines, U87, HCT116, MCF7 and mS, the response was nullified (Figure 2E and Figure S4).

If the more flexible biHD1-C3 molecule has decreased antiproliferative potential, then it is worth to directly compare its activity with properties of single-modular HD1.

Until now, an antiproliferative effect of single-modular GQ HD1 has been shown on the limited number of cell lines such as HeLa, Calu-6 and mutant HCT116 ${ }^{\text {p53-- }}$ [15-18]. In particular, U87 cell lines and embryonic human fibroblasts have not been tested for the antiproliferative activity of HD1. We have directly compared the antiproliferative effect of single-modular GQ HD1 and bimodular GQ biHD1-C3 by MTT test after $72 \mathrm{~h}$ of treatment (Figure 2E,F and Figure S4). Viability of U87 cells had not decreased when treating with HD1 and biHD1-C3 - contrary to biHD1 with 45\% of survival. The human embryonic fibroblast cell line was weakly sensitive to $10 \mu \mathrm{M}$ HD1 treatment with a 10\% decrease in the cell viability.

To introduce possible minor deviations in the GQ structure of biHD1, TT-loops structure/interactions had been changed. In each GQ TT-loops could interact via TT base pair T4-T13 in the 5'-terminal GQ and T20-T29 in the 3'-terminal GQ. In biHD1-T4A,T20A derivative, $\mathrm{T} 4$ and T20 are replaced with adenine residues to change the nature of the base pair partner. These replacements eliminate the antiproliferative activity of biHD1-T4A,T20A for all cell lines-except for the most sensitive lung cancer RL-67 cell line with 50\% cell viability (Figure 2G-I and Figure S5). For all concentrations of biHD1-T4A,T20A, nearly no effect on human embryonic fibroblast cells was observed.

Oligonucleotide biHD1-5'- $\Delta 2 \mathrm{G}$ could only have a single $3^{\prime}$-terminal GQ, because $5^{\prime}$-terminal GQ could not be folded due to the deletion of two $5^{\prime}$-terminal critical G-residues. BiHD1-5'- $\Delta 2 \mathrm{G}$ does not exhibit antiproliferative activity for all cell lines-except for U87 (Figure 2J-L and Figure S6).

The complex of biHD1 with barium cation, biHD1+Ba, has an unusual conformation of both GQs [25]. Interestingly enough, biHD1+Ba does not influence the proliferation of any cell line under study (Figure S7). Barium cation itself could decrease cell viability of some cell lines [30]; therefore, in control experiments, a cytotoxic effect of barium cation was evaluated (Figure S8). Only weak cytotoxic effect of barium cations on RL-67 cell line and fibroblasts have been found, and it is eliminated when barium cation is chelated within biHD1+Ba complex.

\section{Discussion}

Antiproliferative activity of DNA oligonucleotide with G-quadruplex structure (GQ) is well known for more than decades. Bates et al. developed an antiproliferative GQ oligonucleotide AS1411 and made a thorough study aiming to translate AS1411 into the clinic [1,4,5]. Then, HD1, another GQ structure with antiproliferative activity, was discovered [12]. Since then, some other GQ molecules have been identified [2,3], and for some of them $\mathrm{IC}_{50}$ has been determined [3]. Nevertheless, even for the widely studied AS1411, both the exact target and mechanism of action are not yet known [1].

Several strategies for further molecular design could be proceeded either by irrational random selection or rational design. A simple way for rational design is to reveal some minimal functional structures and manipulate them; for example, to assemble them covalently into multi-functional constructs. The creation of multi-modular structures combining several structural or functional modules within a single molecule appears to be a promising approach for drug development. 
A simple example of antiproliferative GQ is a chair-like monomolecular antiparallel GQ, 15-mer HD1 [12]. In some cases, even modified versions of HD1 still exhibit antiproliferative activity [16-18]. Therefore, aiming to explore a possibility to use HD1 as a module for creating more-complex molecules, we decided to make the simplest construct of biHD1 by covalently linking two GQ modules via a single thymidine residue. This 'tween' molecule could lose structure/activity or save structure/activity either completely or with some deviations.

This construct has already been made for other purposes [23], but its structure has not yet been established in detail; it is assumed that the existence of two slightly unequal GQs with a topology of monomolecular antiparallel for each of them are similar to the GQ topology of HD1 [26,28].

Circular dichroism spectroscopy is an ideal method to monitor GQ folding, because every particular topology of GQ has a characteristic spectrum, and the value of molar circular dichroism is proportional to a percentage of GQ fold in the sample. As was shown before in [26], CD spectrum of biHD1 in $5 \mathrm{mM} \mathrm{KCl}$ has maxima at 294 and $247 \mathrm{~nm}$ and minima at 267 and $230 \mathrm{~nm}$, which completely correlates with CD spectrum of initial HD1, but the amplitude of the maximum at $294 \mathrm{~nm}$ is higher. In the current study, a comparison of $\mathrm{CD}$ was made at $10 \mathrm{mM} \mathrm{KCl}$, and it turned out that the maximum of biHD1 is 1.5 times higher than for HD1-which perfectly indicates a folding of additional GQ. The more pronounced difference of values is due to the strict dependence of GQ folding on $\mathrm{KCl}$ concentration (see, for example [25]). CD melting data have proved the stability of GQ structures of biHD1 under conditions of antiproliferative activity testing (Figure S1).

After GQ structure of biHD1 had been proved, the next question is whether HD1 retains its antiproliferative activity. Antiproliferative activities of GQs with different topology vary; there is no molecular mechanism of its activity. Therefore, the very first step to check an antiproliferative potential of biHD1 is to screen the sensitivity of different human cancer cell lines and select suitable ones for further research. Different human cancer cell lines: Melanoma, glioblastoma; lung, breast, intestines and prostate cancer were used in this screening (Table 3). Some cell lines, e.g., HeLa and HCT116 mutant, have already been used to check the antiproliferative effect of HD1 [15-18].

The antiproliferative effect depends on the concentration of GQ, the duration and frequency of treatment. In many cases, the most pronounced effect has been found at high GQ concentration of $50 \mu \mathrm{M}$ [16-18] and a very long duration of 7 days [15] without intermediate treatment. Therefore, for the primary testing in this study, a low concentration range $0.1-10 \mu \mathrm{M}$, of biHD1, with a treatment duration of three days, was selected.

It is generally accepted that the cell viability correlates well with proliferating potential, and that the conventional approach is the MTT test [31]. The MTT test measures cell viability due to the metabolic activity, by a reduction of the water-soluble, yellow tetrazole salt (MTT) into the insoluble dark blue formazan. The amount of reduced MTT is proportional to the number of living cells. MTT is a simple and straightforward approach for sensitivity screening of different sets of both oligonucleotides and cell lines. More valuable information on antiproliferative information could be obtained by direct measuring the amount of proliferating cells, and this was performed for some particular samples after selecting sensitive cell line, U87.

Antigen KI-67 (also known as Ki-67 or MKI67) is a nuclear protein that is strictly associated with cell proliferation, but is absent in resting (quiescent, G0) cells; and hence is a classical cellular marker for proliferation [32,33]. Ki-67 is an excellent marker to measure the growth fraction of a given cell population, identified by monoclonal antibody Ki-67. Even more, the fraction of Ki-67-positive tumor cells (the Ki-67 labeling index) is often correlated with the clinical course of cancer. Therefore, by comparing numbers of proliferating cells (stained with fluorescent Ki-67-antibody, green images) with a total number of cells (stained with bisbenzimide nuclear fluorescent dye, blue images) one could directly estimate an antiproliferative effect of biHD1. 
BiHD1

According to the MTT data, biHD1 has antiproliferative activity for all tested human cancer cell lines. It is the most active for two cell lines: Lung cancer cells RL-67 and CNS cancer cells U87, with a cell viability of less than 50\%, and it is important that the response is dose-dependent (Figure 2A,B and Figure S2, Table 2). Three cell lines with cell viability from $50 \%$ to $80 \%$ are HeLa (as commonly used), colon cancer cells HCT116, and breast adenocarcinoma cells MCF7. Three cell lines have a rather high cell viability from $80 \%$ to $100 \%$ : Prostate cancer cells PC3, melanoma cells mS, and non-cancerous embryonic fibroblasts cell line hEF. It is important to stress that biHD1 does not affect the viability of non-malignant fibroblast cell line (Figure 2C).

Two examples illustrate the idea that there is no uniform mechanism of action of different GQs for different cell lines. Firstly, the cell viability of human embryonic fibroblast cells has decreased to $70 \%$ after treatment with $10 \mu \mathrm{M}$ biHD1-C3 (Figure 3B), and the original biHD1 has no effect. Curiously enough, biHD1-C3 increased proliferation of PC3 prostate cancer cells up to 130\% in a dose-dependent way (Figure S3B).

The MTT assay is a colorimetric assay to measure cell metabolic activity, and not proliferation itself. Nevertheless, the assay is widely applicable to estimate cytotoxicity (loss of viable cells) or cytostatic activity (shift from proliferation to quiescence) of potential anti-cancer agents, because all these parameters are interlinked. Therefore, it could be more informative to evaluate the antiproliferative activity of biHD1 by an independent method, for example, by direct counting of proliferating cells before and after treatment with biHD1.

We focused on the sensitive U87 cell line and compared with the less sensitive MCF7 cell line. Immunohistochemistry results indicated that the number of Ki67-positive cells, indicating proliferating cells, was decreased in the case of U87 cell line (Figure 3) treated with $10 \mu \mathrm{M}$ biHD1. This is not the case for less sensitive MCF7 cells.

To test a hypothesis, which is that the GQ structure could be responsible for the antiproliferative activity, a series of biHD1 derivatives were created (Table 1).

\section{BiHD1-C3}

The two GQs within the original biHD1 are linked via a single thymidine residue, providing a rather compact structure that unfolds in a rather cooperative manner [28]. On the other hand, the antiproliferative activity could be provided either by the entire structure or by an individual GQ itself. Trying to resolve this ambiguity, we made biHD1 derivative, biHD1-C3, with a more flexible linker between two GQs-the propanediol residue. In this case, rather rigid nucleoside moiety is replaced with a flexible three-methylene bridge. The CD spectrum (Figure 1) confirms the idea that a more flexible linker in biHD1-C3 disturbs the original conformations of GQs as compared to biHD1, in which the structures of the two GQs appear to have a reciprocal effect. Thus, biHD1-C3 could have more autonomous GQs. This could affect biHD1-C3 activity, for example, both for the ability to penetrate the cell and for interactions with GQ-binding proteins inside the cell. Indeed, the antiproliferative activity of biHD1-C3 had changed for all cell lines (Figure 2D-F and Figure S3). In general, biHD1-C3 became much less toxic to the cancer cell lines, although the very sensitive lung cancer cell line RL-67 still

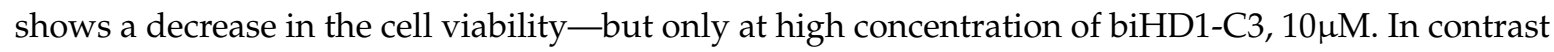
to the original biHD1, biHD1-C3 slightly reduced the viability of control fibroblast cells to $70 \%$ at high concentration; the effect was dose-dependent (Figure 2F).

The most striking example of unusual activity of biHD1-C3 is its effect for the PC3 cell line, where proliferation is even increased by $30 \%$ after treatment with $10 \mu \mathrm{M}$ biHD1-C3. This activity is dose-dependent (Figure S3E). Similar examples of increased cell viability after the addition of an oligonucleotide are described for some other GQs [34].

The properties of biHD1-C3-having more independent GQs-led us to directly compare the properties of bimodular biHD1-C3 and single-modular HD1. 
The antiproliferative effect of HD1 is described in the literature just for several types of cell

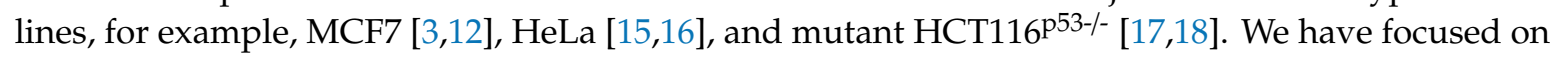
U87 CNS cancer cells. It turned out that HD1 has no antiproliferative activity, exactly as HD1-C3 (Figure S4) - but not as initial biHD1. Therefore-particularly for the U87 cell line-it is in line with an idea that the entire construct of biHD1 is required for the antiproliferative activity—not just GQ itself.

\section{BiHD1-T4A,T20A}

The single-module of HD1 has T4-T13 noncanonical base pair, which fixes a mutual conformation of two lateral TT-loops. This T4-T13 pair stacks on the adjacent G-quartet and stabilizes GQ [14]. In biHD1-T4A,T20A derivative, two thymines from both TT-loops, T4 and T20, were replaced with two adenines, producing T-A juxtaposition instead of TT base pair. Due to the obvious different geometry of T-A and T-T, some conformational distortions could be expected. Indeed, the CD spectrum of biHD1-T4A,T20A shows deviations from the original conformation of biHD1 (Figure 1). The possible conformational changes are not obvious, and computer MD modeling is now in progress. In any case, biHD1-T4A,T20A loses antiproliferative activity for almost all cell lines. Again, the only exception is sensitive RL-67 cell line, which exhibits sensitivity, but for the high concentration $10 \mu \mathrm{M}$ biHD1-T4A,T20A (Figure 2G-I and Figure S5).

\section{$B i H D 1-5^{\prime}-\Delta 2 G$}

To check the hypothesis that the antiproliferative activity requires a GQ structure of biHD1, biHD1-5'- $\Delta 2 \mathrm{G}$ molecule was designed. The 5'-terminal GQ could not fold due to the deletion of critical $5^{\prime}$-terminal two Gs forming GQ. For the single-module of HD1, the lack of the $5^{\prime}$-terminal two Gs could yield an alternative structure under certain conditions (G-triplex, instead of G-quadruplex), but the stability of this conformation is low [35]. Indeed, in the CD spectrum of biHD1-5'- $\Delta 2 G$, there is a strong decrease in the amplitude of $294 \mathrm{~nm}$ (Figure 1). The value is two times lower than for the initial biHD1, but not as low as the value for completely unfolded biHD1 [25]. Not surprisingly, the antiproliferative activity of biHD1-5'- $\Delta 2 \mathrm{G}$ is significantly reduced for almost all cell lines (Figure 2J-L and Figure S6). This means that the $5^{\prime}$-terminal GQ module plays an essential role in the antiproliferative activity of bimodular biHD1. The sensitive cell line RL-67 has an ideal response to GQ conformational disordering: biHD1-5'- $\Delta 2 \mathrm{G}$ does not show antiproliferative activity at all.

Table 3. List of the human cancer cell lines and the control cell line.

\begin{tabular}{cccc}
\hline Number & Name & Cell Line & Reference \\
\hline 1 & RL-67 & Lung cancer & {$[36]$} \\
\hline 2 & U87 & Central nervous system cancer & {$[37]$} \\
\hline 3 & HeLa & Epithelioid cervix carcinoma & {$[38]$} \\
\hline 4 & HCT116 & Colon cancer & {$[39]$} \\
\hline 5 & MCF7 & Breast adenocarcinoma & {$[40]$} \\
\hline 6 & mS & Melanoma & {$[41]$} \\
\hline 7 & PC3 & Prostate cancer & {$[42,43]$} \\
\hline 8 & hEF & Human embryonic fibroblasts & {$[44]$} \\
\hline
\end{tabular}

\section{$\mathrm{BiHD} 1+\mathrm{Ba}$}

Finally, what happened when both GQs of biHD1 would be fixed by a strong chelating cation, similar to barium in the 'biHD1+Ba' molecule? It is well known that $\mathrm{Ba}^{2+}$ is strongly chelated into the 
central cavity of GQ and stiffens it [29]. Moreover, the conformation of 'HD1+Ba' is not able to interact with the target protein (thrombin), normally interacting with HD1 [25].

The CD spectrum of biHD1+Ba differs significantly from the spectra of other derivatives of biHD1 (Figure 1). Similar to HD1 [25] the magnitude of biHD1+Ba CD spectrum maximum of antiparallel GQ is significantly increased (by 1.5 times) and shifted to $300 \mathrm{~nm}$.

For almost all cell lines, there is no antiproliferative effect at all concentrations of biHD1+Ba (Figure S7). This observation supports an idea that a certain GQ conformation or conformational flexibility of GQ is required for the antiproliferative activity of biHD1, which is in line with the behavior of other GQs+Ba and their targets.

\section{Materials and Methods}

\subsection{Oligodeoxyribonucleotides (ODN)}

DNA oligonucleotides were synthesized and HPLC-purified by Evrogen Ltd. (Moscow, Russia). The nucleotide sequences of ODNs are provided in Table 1. Salts for buffers were of analytical grade purity from MP Biomedicals (France). The $100 \mu \mathrm{M}$ ODN stock solutions were prepared in $10 \mathrm{mM}$ $\mathrm{NaH}_{2} \mathrm{PO}_{4} / \mathrm{Na}_{2} \mathrm{HPO}_{4}, 10 \mathrm{mM} \mathrm{KCl}$ and $140 \mathrm{mM} \mathrm{NaCl}$ with $\mathrm{pH}$ of 7.5 (PBS). The ODN solutions were subjected to annealing procedure: Heating to $95{ }^{\circ} \mathrm{C}$, then slow cooling to $25^{\circ} \mathrm{C}$. A two-fold molar excess of barium chloride was added to biHD1 to prepare 'biHD1+Ba' samples.

\subsection{Circular Dichroism Spectroscopy}

Circular dichroism spectroscopy (CD) samples of oligonucleotides were prepared with $2.5 \mu \mathrm{MODN}$ (5 $\mu \mathrm{M}$ for HD1) in phosphate-buffered saline $\left(10 \mathrm{mM} \mathrm{NaH} \mathrm{PO}_{4} / \mathrm{Na}_{2} \mathrm{HPO}_{4}, 10 \mathrm{mM} \mathrm{KCl}, 140 \mathrm{mM} \mathrm{NaCl}\right.$, pH 7.5, PBS). CD spectra were registered on CD spectrometer CHIRASCAN (Applied Photophysics, Leatherhead, Surrey, UK) and dichrograph MARK-5 (Jobin-Yvon, Bensheim, Germany). Quartz cuvettes with an optical path length of $1 \mathrm{~cm}$ were used. CD spectra were registered in the wavelength range from 220 to $340 \mathrm{~nm}$ at the scan rate of $120 \mathrm{~nm} \mathrm{~min}^{-1}$, with a response of $2 \mathrm{~s}$ at $2.0 \mathrm{~nm}$ bandwidth, and normalized by subtraction of the background scan with buffer only. The temperature was kept constant at $20^{\circ} \mathrm{C}$ with a thermoelectrically controlled cell holder. The $\mathrm{CD}$ signal was recalculated as molar circular dichroism, $\Delta \epsilon\left(\mathrm{cm}^{-1} \mathrm{M}^{-1}\right)$.

All data processing and calculations were performed using the OriginPro 8.0 software (Origin Lab Corporation, Northampton, MA, USA).

\subsection{Cell Lines and MTT Assay}

Cell lines are listed in Table 1. The RL-67 and mS cell lines were kindly provided by N.N. Blokhin National Medical Research Center of Oncology, Russia. The other cell lines were purchased from the Institute of Cytology, Russian Academy of Science, St.Petersburg, Russia. Cells were cultured in Dulbecco's modified medium (DMEM, Gibco, USA) supplemented with $10 \%$ fetal bovine serum (FBS, Thermo Fisher Scientific, Waltham, MA, USA) at $5 \% \mathrm{CO}_{2}$ at $37^{\circ} \mathrm{C}$.

The cell viability was measured by MTT test using colorimetric measurements of metabolic activity of viable cells. The cells were seeded into 96-well plates with a density of $3 \times 10^{3}$ cells per well and incubated for $24 \mathrm{~h}$ at $37^{\circ} \mathrm{C}$. Then, the medium was replaced with a $50 \%$ solution of medium with ODN at various concentrations $(0.10,1.0$ and $10 \mu \mathrm{M})$ or phosphate buffer only. The cells were incubated for three days. Then, $20 \mu \mathrm{L}$ of $5 \mathrm{mg} / \mathrm{mL}$ MTT reagent (3-(4,5-dimethylthiazol-2-yl)-2,5-diphenyltetrazolium bromide) (Sigma-Aldrich, USA) was added to each well, and the incubation was continued for $2 \mathrm{~h}$ at $37^{\circ} \mathrm{C}$. The medium was removed from the wells and $60 \mu \mathrm{L} /$ well of DMSO (PanEco Ltd., Russia) was added, stirred for $15 \mathrm{~min}$, and the absorbance at $540 \mathrm{~nm}$ was measured using Tecan plate reader (Tecan Group Ltd, Männedorf, Switzerland). The data were normalized to MTT results for the cells without ODN; the results represent the mean \pm SEM of $n=5$ repeats. 


\subsection{Immunohistochemistry}

U87 and MCF7 cells were grown in a 4-well plate, $1 \times 10^{5}$ cells per well. Cells were incubated with biHD1 solutions with final concentrations of $0.10,1.0$ and $10 \mu \mathrm{M}$ in PBS or PBS without ODN in $50 \%$ cell medium for $72 \mathrm{~h}$ at $37^{\circ} \mathrm{C}$ and $5 \% \mathrm{CO}_{2}$. Cells were washed three times with PBS, and the solution of $3.7 \%$ formaldehyde in phosphate buffer was added to each well for fixation, the cells were washed three times with PBS. The primary antibody to the Ki-67 protein proliferation marker (NCL-Ki67p, Novocastra Laboratories, Newcastle upon Tyne, UK) with $0.1 \%$ Triton $\times 100$ was added to the cells for $1 \mathrm{~h}$ at $20^{\circ} \mathrm{C}$. Cells were washed with PBS three times, then secondary antibody conjugated with the fluorescent dye Cy2 (Cy2-conjugated AffiniPure donkey anti-rabbit, cat.no 711-225-152, Jackson ImmunoResearch, Cambridgeshire, UK) was added to the cells for $1 \mathrm{~h}$. After washing three times with PBS, the cells were tinted with a bisbenzimide nuclear fluorescent dye (H33342, Sigma-Aldrich Corp., St. Louis, MO, USA). The cells were photographed using an Olympus IX81 inverted fluorescence microscope (Olympus Corporation, Tokio, Japan) equipped with a D-70 digital camera (Leica Camera AG, Wetzlar, Germany) applying two modes to register the fluorescence of the $\mathrm{Cy} 2$ dye and bisbenzimide. For each well, six representative images were randomly captured. The percentages of Ki-67 positive cells were quantified by a masked researcher. For every captured area, the amount of Ki-67 positive cells (stained with Cy2) and the total amount of cells (stained with bisbenzimide) were counted. Ki-67 negative cells were not stained with Cy2. In total, for each dose of biHD1 more than 600 cells were analyzed.

\subsection{Statistical Analysis}

Statistica 13.0 software (StatSoft, Tulsa, OK, USA) was used for data analysis. The data are shown as \pm SD. Analysis of variance was used to evaluate statistical differences between groups. The $\chi 2$ test was applied to evaluate the difference between the enumeration data of different groups. The Mann-Whitney test was used to determine the mean number of Ki-67-positive cells per field. A statistically significant difference was assumed for $p<0.05$.

\section{Conclusions}

Building a novel molecular construct by combining several functional units (modules) is a perspective direction of a molecular design, and oligonucleotides are very suitable molecules to perform these tasks. Development of nucleic acids therapeutics requires intensification of this direction as well.

Here, a feasibility of building of antiproliferating bimodular construct by covalently linking two antiproliferative DNA antiparallel G-quadruplex (GQ) 15-mers (HD1) have been demonstrated. Antiproliferative activities of bimodular GQ biHD1 and its derivatives were tested using eight different human cancer cell lines: Lung cancer RL-67, central nervous system cancer U87, epithelioid cervix carcinoma HeLa, colon cancer HCT116, breast adenocarcinoma MCF7, melanoma mS, prostate cancer PC3, and a control non-malignant human embryonic fibroblast-hEF. Antiproliferative effects of biHD1 vary for different cell lines; therefore, there is a lack of unique mechanism. BiHD1 does not inhibit proliferation of control non-cancerous hEF. BiHD1 exhibits a dose-dependent antiproliferative activity for RL-67 and U87. The study of derivatives of biHD1 for RL-67 and U87 revealed a strict structure-activity correlation of GQ folding and antiproliferative activity.

These initial results are bases from where to further explore the antiproliferative properties of GQs and to study the following topics: How does GQ penetrate into the cells; molecular and cellular mechanisms; what is a target; and others. This research provides an experimental support for the development of new GQ-based antiproliferative agents either as GQ itself or as a carrier.

Supplementary Materials: Supplementary Materials are available online.

Author Contributions: Conceptualization, E.Z. and A.K., investigation, O.A., N.S., A.R. and E.S.; data curation, O.A. and E.Z.; writing-original draft preparation, O.A.; writing—review and editing, O.A., G.P. and A.K.; supervision, G.P. and A.K.; funding acquisition, G.P. 
Funding: The authors acknowledge Rybalkina O.Yu. (N.N. Blokhin National Medical Research Center of Oncology, Ministry of Health of the Russian Federation) for kindly provided cell lines mS and RL-67. The study was funded by RFBR KOMFI according to the research project number 17-00-00160 and number 17-00-00157 (17-00-00162 (K)).

Conflicts of Interest: The authors declare no conflict of interest.

\section{References}

1. Bates, P.J.; Reyes-Reyes, E.M.; Malik, M.T.; Murphy, E.M.; O’Toole, M.G.; Trent, J.O. G-quadruplex oligonucleotide AS1411 as a cancer-targeting agent, Uses and mechanisms. Biochim. Biophys. Acta Gen. Subj. 2017, 861, 1414-1428.2. [CrossRef] [PubMed]

2. Chang, T.; Qi, C.; Meng, J.; Zhang, N.; Bing, T.; Yang, X.; Cao, Z.; Shangguan, D. General cell-binding activity of intramolecular G-quadruplexes with parallel structure. PLoS ONE 2013, 8, e62348. [CrossRef] [PubMed]

3. Ogloblina, A.M.; Khristich, A.N.; Karpechenko, N.Y.; Semina, S.E.; Belitsky, G.A.; Dolinnaya, N.G.; Yakubovskaya, M.G. Multi-targeted effects of G4-aptamers and their antiproliferative activity against cancer cells. Biochimie 2018, 145, 163-173. [CrossRef] [PubMed]

4. Bates, P.J.; Laber, D.A.; Miller, D.M.; Thomas, S.D.; Trent, J.O. Discovery and development of the G-rich oligonucleotide AS1411 as a novel treatment for cancer. Exp. Mol. Pathol. 2009, 86, 151-164. [CrossRef] [PubMed]

5. Rosenberg, J.E.; Bambury, R.M.; Van Allen, E.M.; Drabkin, H.A.; Lara, P.N., Jr.; Harzstark, A.L.; Figlin, R.A.; Smith, G.W.; Garraway, L.A.; Choueiri, T.; et al. A phase II trial of AS1411 (a novel nucleolin-targeted DNA aptamer) in metastatic renal cell carcinoma. Invest. New Drugs 2014, 32, 178-187. [CrossRef] [PubMed]

6. Gao, P.; Niu, N.; Wei, T.; Tozawa, H.; Chen, X.; Zhang, C.; Zhang, J.; Wada, Y.; Kapron, C.M.; Liu, J. The roles of signal transducer and activator of transcription factor 3 in tumor angiogenesis. Oncotarget 2017, 8, 69139-69161. [CrossRef] [PubMed]

7. Jing, N.; Li, Y.; Xu, X.; Sha, W.; Li, P.; Feng, L.; Tweardy, D.J. Targeting Stat3 with G-Quartet Oligodeoxynucleotides in Human Cancer Cells. DNA Cell Biol. 2003, 22, 685-696. [CrossRef] [PubMed]

8. Gu, H.; Li, D.; Sung, C.K.; Yim, H.; Troke, P.; Benjamin, T. DNA-binding and regulatory properties of the transcription factor and putative tumor suppressor p150Sal2. Biochim. Biophys. Acta Gene Regul. Mech. 2015, 1809, 276-283. [CrossRef]

9. Hu, J.; Zhao, Z.; Liu, Q.; Ye, M.; Hu, B.; Wang, J.; Tan, W. Study of the Function of G-Rich Aptamers Selected for Lung Adenocarcinoma. Chem. Asian J. 2015, 10, 1519-1525. [CrossRef]

10. Nonaka, Y.; Sode, K.; Ikebukuro, K. Screening and Improvement of an Anti-VEGF DNA Aptamer. Molecules 2010, 15, 215. [CrossRef]

11. Bock, L.C.; Griffin, L.C.; Latham, J.A.; Vermaas, E.H.; Toole, J.J. Selection of single-stranded DNA molecules that bind and inhibit human thrombin. Nature 1992, 355, 564-566. [CrossRef] [PubMed]

12. Dapić, V.; Abdomerović, V.; Marrington, R.; Peberdy, J.; Rodger, A.; Trent, J.O.; Bates, P.J. Biophysical and biological properties of quadruplex oligodeoxyribonucleotides. Nucleic Acids Res. 2003, 31, 2097-2107. [CrossRef] [PubMed]

13. Trajkovski, M.; Sket, P.; Plavec, J. Cation localization and movement within DNA thrombin binding aptamer in solution. Org. Biomol. Chem. 2009, 7, 4677-4684. [CrossRef]

14. Russo Krauss, I.; Merlino, A.; Randazzo, A.; Novellino, E.; Mazzarella, L.; Sica, F. High-resolution structures of two complexes between thrombin and thrombin-binding aptamer shed light on the role of cations in the aptamer inhibitory activity. Nucleic Acids Res. 2012, 40, 8119-8128. [CrossRef] [PubMed]

15. Kotkowiak, W.; Lisowiec-Wachnicka, J.; Grynda, J.; Kierzek, R.; Wengel., J.; Pasternak, A. Thermodynamic, Anticoagulant, and Antiproliferative Properties of Thrombin Binding Aptamer Containing Novel UNA Derivative. Mol. Ther. Nucleic Acids 2018. [CrossRef] [PubMed]

16. Scuotto, M.; Rivieccio, E.; Varone, A.; Corda, D.; Bucci, M.; Vellecco, V.; Cirino, G.; Virgilio, A.; Esposito, V.; Galeone, A.; et al. Site specific replacements of a single loop nucleoside with a dibenzyl linker may switch the activity of TBA from anticoagulant to antiproliferative. Nucleic Acids Res. 2015, 43, 7702-7716. [CrossRef] [PubMed]

17. Esposito, V.; Russo, A.; Amato, T.; Varra, M.; Vellecco, V.; Bucci, M.; Russo, G.; Virgilio, A.; Galeone, A. Backbone modified TBA analogues endowed with antiproliferative activity. Biochim. Biophys. Acta Gen. Subj. 2018, 1861, 1213-1221. [CrossRef] [PubMed] 
18. Esposito, V.; Russo, A.; Amato, T.; Vellecco, V.; Bucci, M.; Mayol, L.; Russo, G.; Virgilio, A.; Galeone, A. The "Janus face" of the thrombin binding aptamer: Investigating the anticoagulant and antiproliferative properties through straightforward chemical modifications. Bioorg. Chem. 2018, 76, 202-209. [CrossRef] [PubMed]

19. Zavyalova, E.; Kopylov, A. DNA aptamer-based molecular nanoconstructions and nanodevices for diagnostics and therapy. In Nanostructures for the Engineering of Cells, Tissues and Organs; Grumezescu, A.M., Ed.; William Andrew Publishing: New York, NY, USA, 2018; pp. 249-290.

20. Zavyalova, E.G.; Legatova, V.A.; Alieva, R.S.; Zalevsky, A.O.; Tashlitsky, V.N.; Arutyunyan, A.M.; Kopylov, A.M. Putative mechanisms underlying high inhibitory activities of bimodular DNA aptamers to Thrombin. Biomolecules 2019, 9, E41. [CrossRef] [PubMed]

21. Kortylewski, M.; Nechaev, S. How to Train Your Dragon, Targeted Delivery of MicroRNA to Cancer Cells In Vivo. Mol. Ther. 2014, 22, 1070-1071. [CrossRef] [PubMed]

22. Soldevilla, M.M.; Meraviglia-Crivelli de Caso, D.; Menon, A.P.; Pastor, F. Aptamer-iRNAs as Therapeutics for Cancer Treatment. Pharmaceuticals (Basel) 2018, 11, E108. [CrossRef] [PubMed]

23. Golovin, A.V.; Kopylov, A.M.; Reshetnikov, R.V.; Zavyalova, E.G.; Pavlova, G.V.; Babiy, V.E. Anti-Thrombosis Aptamers and Method for Stabilizing the Structure Thereof. WO2011075004A1, 23 June 2011.

24. Zavyalova, E.; Samoylenkova, N.; Revishchin, A.; Turashev, A.; Gordeychuk, I.; Golovin, A.; Kopylov, A.; Pavlova, G. The Evaluation of Pharmacodynamics and Pharmacokinetics of Anti-thrombin DNA Aptamer RA-36. Front. Pharmacol. 2017, 8, 922. [CrossRef]

25. Zavyalova, E.; Tagiltsev, G.; Reshetnikov, R.; Arutyunyan, A.; Kopylov, A. Cation Coordination Alters the Conformation of a Thrombin-Binding G-Quadruplex DNA Aptamer That Affects Inhibition of Thrombin. Nucleic Acid Ther. 2016, 26, 299-308. [CrossRef] [PubMed]

26. Yuminova, A.V.; Smirnova, I.G.; Arutyunyan, A.M.; Kopylov, A.M.; Golovin, A.V. The structure of G-quadruplex thrombin binding DNA-aptamer RA-36. Moscow Univ. Chem. Bull. 2015, 56, 44-48.

27. Amato, T.; Virgilio, A.; Pirone, L.; Vellecco, V.; Bucci, M.; Pedone, E.; Esposito, V.; Galeone, A. Investigating the properties of TBA variants with twin thrombin binding domains. Sci. Rep. 2019, 9, 9184. [CrossRef] [PubMed]

28. Zavyalova, E.; Golovin, A.; Pavlova, G.; Kopylov, A. Module-activity relationship of G-quadruplex based DNA aptamers for human thrombin. Curr. Med. Chem. 2013, 20, 4836-4843. [CrossRef] [PubMed]

29. Reshetnikov, R.V.; Sponer, J.; Rassokhina, O.I.; Kopylov, A.M.; Tsvetkov, P.O.; Makarov, A.A.; Golovin, A.V. Cation binding to 15-TBA quadruplex DNA is a multiple-pathway cation-dependent process. Nucleic Acids Res. 2011, 39, 9789-9802. [CrossRef]

30. Newsholme, P.; Adogu, A.A.; Soos, M.A.; Hales, C.N. Complement-induced Ca2+ influx in cultured fibroblasts is decreased by the calcium-channel antagonist nifedipine or by some bivalent inorganic cations. Biochem. J. 1993, 295, 773-779. [CrossRef] [PubMed]

31. Muñoz-Moreno, L.; Arenas, M.I.; Carmena, M.J.; Schally, A.V.; Sánchez-Chapado, M.; Prieto, J.C.; Bajo, A.M. Anti-proliferative and pro-apoptotic effects of GHRH antagonists in prostate cancer. Oncotarget 2016, 7, 52195-52206. [CrossRef]

32. Sun, X.; Kaufman, P.D. Ki-67: More than a proliferation marker. Chromosoma 2018, 127, 175-186. [CrossRef]

33. Menon, S.S.; Guruvayoorappan, C.; Sakthivel, K.M.; Rasmi, R.R. Ki-67 protein as a tumour proliferation marker. Clin. Chim. Acta 2019, 491, 39-45. [CrossRef] [PubMed]

34. Zhang, N.; Bing, T.; Liu, X.; Qi, C.; Shen, L.; Wang, L.; Shangguan, D. Cytotoxicity of guanine-based degradation products contributes to the antiproliferative activity of guanine-rich oligonucleotides. Chem. Sci. 2015, 6, 3831-3838. [CrossRef] [PubMed]

35. Cerofolini, L.; Amato, J.; Giachetti, A.; Limongelli, V.; Novellino, E.; Parrinello, M.; Fragai, M.; Randazzo, A.; Luchinat, C. G-triplex structure and formation propensity. Nucleic Acids Res. 2014, 42, 13393-13404. [CrossRef] [PubMed]

36. Lopatina, K.A.; Razina, T.G.; Zueva, E.P.; Krylova, S.G.; Guryev, A.M.; Amosova, E.N.; Rybalkina, O.Y.; Safonova, E.A.; Efimova, L.A.; Belousov, M.V. Preclinical studies of $\alpha(1,2)$-L-ramno- $\alpha(1,4)$-D-galactopiranoziluronan from rhizomes Acorus calamus L. in cancer experiment. Sib. J. Oncol. 2015, 1, 59-63.

37. Allen, M.; Bjerke, M.; Edlund, H.; Nelander, S.; Westermark, B. Origin of the U87MG glioma cell line, Good news and bad news. Sci. Transl. Med. 2016, 8, 354re3. [CrossRef] [PubMed] 
38. Chen, T.R. Re-evaluation of HeLa, HeLa S3, and HEp-2 karyotypes. Cytogenet. Genome Res. 1988, 4, $19-24$. [CrossRef] [PubMed]

39. Brattain, M.G.; Fine, W.D.; Khaled, F.M.; Thompson, J.; Brattain, D.E. Heterogeneity of malignant cells from a human colonic carcinoma. Cancer Res. 1981, 41, 1751-1756.

40. Soule, H.D.; Vazguez, J.; Long, A.; Albert, S.; Brennan, M. A human cell line from a pleural effusion derived from a breast carcinoma. J. Nat. Cancer Inst. 1973, 51, 1409-1416. [CrossRef]

41. Stromskaya, T.P.; Filippova, N.A.; Rybalkina, E.Yu.; Egudina, S.V.; Shtil, A.A.; Eliseenkova, A.V.; Stavrovskaya, A.A. Alterations of melanin synthesis in human melanoma cells selected in vitro for multidrug resistance. Exp. Toxicol. Pathol. 1995, 47, 157-166. [CrossRef]

42. Chen, T.R. Chromosome identity of human prostate cancer cell lines, PC-3 and PPC-1. Cytogenet. Cell Genet. 1993, 62, 183-184. [CrossRef]

43. Kaighn, M.E.; Narayan, K.S.; Ohnuki, Y.; Lechner, J.F.; Jones, L.W. Establishment and characterization of a human prostatic carcinoma cell line (PC-3). Invest. Urol. 1979, 17, 16-23. [PubMed]

44. Amit, M.; Margulets, V.; Segev, H.; Shariki, K.; Laevsky, I.; Coleman, R.; Itskovitz-Eldor, J. Human Feeder Layers for Human Embryonic Stem Cells. Biol. Reprod. 2003, 68, 2150-2156. [CrossRef] [PubMed]

Sample Availability: Samples of the compounds are available from the authors. 